\title{
PRISIÓN Y SOCIEDAD. MIRADA PANORÁMICA DESDE LA PERSPECTIVA DE GÉNERO
}

Carmen Ruidíaz García

Universidad de La Rioja

RESUMEN: En nuestro contexto cultural y científico las prisiones existen y persisten como males necesarios. En España, nada más iniciar la andadura democrática, se aprobó el marco normativo -Ley Orgánica 1/1979, de 26 de septiembre, General Penitenciaria- que puso el punto de inflexión en la reeducación y reinserción social de las personas presas.

En esta larga historia muchas cosas han cambiado en nuestro sistema penitenciario. Una de las más significativas y/o llamativas es, sin duda, la atención especial a las necesidades de las mujeres que están cumpliendo en un centro penitenciario o están sometidas a medidas alternativas al internamiento en prisión.

En este artículo, a modo de pinceladas de la realidad, se presentan cifras y prácticas socioeducativas significativas desarrolladas en los últimos años para mejorar la calidad de vida de las mujeres presas.

Palabras clave: Prisión, ejecución penitenciaria, género.

\section{PRISON AND SOCIETY. PANORAMIC VIEW FROM THE GENDER PERSPECTIVE}

ABSTRACT: In our cultural and scientific context, prison exists and persist as a necessary evil. In Spain, just start the democratic path, was approved the regulatory framework -Act 1/1979 of 26 September, General Penitentiary- which put the turning point in the rehabilitation and social reintegration of prisoners.

In this long history, many things have changed in our prison system. One of the most significant and/or striking is undoubtedly special attention to the needs of women who are serving in a prison or are subject to alternative measures. 
In this article, by way of the touches of reality, will be presented figures and significant socio practices developed in recent years to improve the quality of life of women prisoners.

Keywords: Imprisonment, execution, prison, gender.

\section{Introducción}

Deseo comenzar estas líneas parafraseando a $M^{a}$ Jesús Miranda López, Cár-

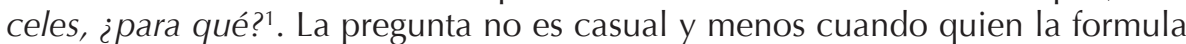
es una de las mujeres españolas más comprometidas con la "cuestión penitenciaria" en la España democrática desde su triple condición de académica, gestora pública y feminista.

Intentando dar una respuesta rápida a la pregunta planteada por Ma Jesús Miranda, tengo que reconocer que en nuestro contexto cultural y científico es común argumentar que las prisiones son un mal necesario, males necesarios que lo mismo tienen que servir como instrumentos de represión como de integración social ayudando a cubrir carencias formativas, de salud, de hábitos de trabajo, etc. de las personas, hombres y mujeres, que no han tenido oportunidades antes de ingresar en las instituciones de control o no han sabido aprovecharlas con éxito.

\section{Breve incursión en los modelos y fundamentos de la pena de prisión}

La reclusión obligada -sea de carácter preventivo, provisional o duraderacon la intención de sancionar algún tipo de delito, de proteger a la sociedad de determinados individuos, o simplemente de servirse de ellos para la realización de trabajos forzado, forma parte de un proceso histórico.

Desde mi punto de vista, la pena de prisión, o cárcel, aparece y se consolida en la historia de la humanidad como una respuesta a las exigencias de racionalización del Derecho y del Estado y del humanismo de las pena. Se configura como institución destinada a la ejecución de la pena privativa de libertad, última instancia de los órganos administradores de la justicia dentro de los órganos de control del Estado. ${ }^{2}$

1. MIRANDA LÓPEZ, Ma J. (2002): "Cárceles, ¿para qué?". Política y Sociedad 39 (2), pp. 377-397.

2. Parafraseando a García Valdés (1980), es en los siglos XVII y XVIII cuando la privación de libertad comenzará a instrumentalizarse como una pena misma, debido sobre todo a dos razones: la primera, tiene su origen en la evolución "humanitaria" de la filosofía penal que adoptarán los nuevos Estados europeos, con la intención de disminuir la aplicación de castigos denigrantes, que provocasen mutilaciones o que derivasen en la muerte; la segunda, vendría motivada por razones de tipo económico y de aprovechamiento de los presos por parte de los poderes establecidos como mano de obra barata e, incluso, gratuita. De tal forma que la prisión, conservando su función procesal, adquirió una función típicamente penal, como retribución y castigo del condenado y como prevención general o ejemplo disuasor para todos los 
El modelo carcelario más citado y de mayor influencia en nuestra cultura jurídica ha sido el ideado por J. Bentham, un modelo que perseguía el objetivo de que cada uno se convierta en vigilante de sí mismo (esencia de la racionalidad disciplinaria, las cadenas son sustituidas por la mirada).

Más recientemente, E. Goffman, nos hace bajar a los sótanos del infierno demostrando que en las cárceles y en los establecimientos psiquiátricos la vida de los internos es objeto de una vigilancia sistemática y de un cúmulo de normas que, lejos de propiciar las iniciativas personales, reducen la vida a un conjunto de ceremoniales heredados.

Por su parte, M. Foucault describe la violencia institucional de los establecimientos cerrados. Las cárceles son consideradas como instrumentos represivos controlados por el Estado que contribuyen a perpetuar la posición de subordinación de las clases dominadas. M. Foucault no abogó por la demolición de las cárceles. Simplemente se limitó a demostrar que no servían para aquello que decían servir y desveló sus funciones sociales: sometimiento de los cuerpos y las almas.

Cabe decir que las investigaciones genealógicas de M. Foucault fueron instrumentalizadas en los años setenta por los partidarios de la desinsticionalización. El ejemplo más destacado es el del catedrático de derecho penal de la Facultad de Derecho de la Universidad de Rotterdan Louk Hulsman y J. Bernat de Celis, para quienes nuestro modelo de sistema penal es un mal social.

L. Hulsman y J. Bernat de Celis sostienen que la cárcel es un mecanismo sin alma. Las reglas de la vida en prisión hacen prevalecer las relaciones de privacidad-agresividad y de dependencia-dominación; no dejan prácticamente lugar alguno para la iniciativa y el diálogo. Igualmente, el sistema penal al castigar a los más débiles crea y refuerza las desigualdades sociales y genera un estigma que afecta a los condenados, a sus familiares y amigos. Como alternativa, desprofesionalización, desinstitucionalización y descentralización. En suma, disminuir la presencia del Estado en la vida de los particulares. ${ }^{3}$

ciudadanos. Al mismo tiempo suponía una protección para la sociedad al aislar a los criminales durante un periodo de tiempo más o menos largo.

Será a finales del siglo XVIII cuando surgirán los primeros movimientos tendentes a dotar de nuevos significados humanizadotes a la ejecución penal, sobreponiéndose al estado en el que se encontraban las cárceles, mejorando las condiciones de vida en las mismas, diferenciando a los condenados en base a situación procesal-penal y a la tipología delictiva.

3. Otros autores que han creado "escuela":

- COHEN, STANLEY (1985): Visions of Social Control. Cambridge, Polity Press (trad. castellana de E. LARRAURI, Visiones de control social. Barcelona, P.P.U., 1988)

- LARRAURI PIJOAN, ELENA (1998a): "Criminología crítica: abolicionismo y garantismo", Nueva doctrina Penal, b:719-753.

- LARRAURI PIJOAN, ELENA (1998b): "Control del delito y castigo en Estados Unidos", introducción a A. VON HIRSCH, Censurar y Castigar. Madrid, Trotta.

- MELOSSI, DARIO con MASSIMO PAVARINI (1977): Carcere e fabbrica. Alle origini del sistema penitenziario. XVI-XIX. Florencia, II Mulino Ed. Versión castellana de Xavier Massimi, (1980) Cárcel y fábrica. Los orígenes del sistema penitenciario. (siglos XVI-XIX). México, Siglo XXI Ed. 
Más sin perder de vista estos modelos teóricos, en nuestro ámbito cultural y científico se ha fraguado y desarrollado un movimiento por la humanización del castigo consolidando sistemas penitenciarios proclives a la resocialización y a la rehabilitación social de las personas condenadas a prisión, al amparo de los principios morales de la Ilustración y de las primeras declaraciones de los Derechos Humanos, cuyo ejemplo paradigmático de los avances normativos que se producen a lo largo del siglo XX lo tenemos en nuestro país.

En España el artículo 25.2 de la Constitución de 1978 marca las directrices de las penas privativas de libertad y las medidas de seguridad. Este marco legal se fue reforzado por una normativa específica propia de nuestro sistema penal ${ }^{5}$ que determina, como es el caso de la L.O.G.P. (Ley Orgánica 1/1979, de 26 de septiembre, General Penitenciaria) las pautas por las que se rige el sistema penitenciario centrado en la rehabilitación y reinserción social de los reclusos. ${ }^{6}$

Por lo demás, pocos objetivos cuentan con tal profusión de declaraciones formales y con tantas críticas dirigidas desde distintos frentes como el principio

- MORRIS, NORVAL (1974): The Future of Imprisonment. Studies in Crime and Justice. Universidad de Chicago Ed. Versión castellana de Nicolás Grab (1978) El futuro de las prisiones. México, Siglo XXI.

- NEUMAN, ELÍAS (1974): Neuman y otros, La sociedad carcelaria. Buenos Aires, Depalma.

- WAQUANT, LÖIC (2000): Las cárceles de la miseria. Buenos Aires, Manantial.

4. La Constitución Española de 1978, en su artículo 25.2, es clara y contundente sobre la función de las penas privativas de libertad y las medidas de seguridad: Las penas privativas de libertad y las medidas de seguridad estarán orientadas hacia la reeducación y reinserción social y no podrán consistir en trabajos forzados. El condenado a pena de prisión que estuviere cumpliendo la misma gozará de los derechos fundamentales de este Capítulo, a excepción de los que se vean expresamente limitados por el contenido del fallo condenatorio, el sentido de la pena y la Ley penitenciaria. En todo caso, tendrá derecho a un trabajo remunerado y a los beneficios correspondientes de la Seguridad Social, así como al acceso a la cultura y al desarrollo integral de su personalidad. Un imperativo legal que se trasladará casi literalmente al artículo 1 del Título Preliminar de la Ley Orgánica 1/1979, de 26 de septiembre, General Penitenciaria (LOGP), prologado en el artículo tercero, en cuyo texto se señala que la actividad penitenciaria se ejercerá respetando, en todo caso, la personalidad humana de los recluidos y los derechos e intereses jurídicos de los mismos no afectados por la condena, sin establecerse diferencia alguna por razón de raza, opiniones políticas, creencias religiosas, condición social o cualquiera otras circunstancias de análoga naturaleza.

5. La normativa penitenciaria en la que se asienta nuestro sistema penitenciario está constituida por:

- La Ley General Orgánica Penitenciaria 1/79 de 26 de septiembre.

- El Reglamento Penitenciario, Real Decreto 190/1996, de 9 de febrero.

- Diferentes Circulares e Instrucciones del Centro Directivo.

También hay que contemplar otra normativa en la que se basa el Sistema penitenciario español):

- Código Penal L. O. 10/1995, de 23 de noviembre.

- Ley de Enjuiciamiento Criminal.

- Reglamento que regula la ejecución de las penas de trabajo en beneficio de la comunidad y arrestos de fin de semana. Real Decreto 690/1996, de 26 de abril.

6. En el preámbulo de la L.O.G.P. (Ley Orgánica 1/1979, de 26 de septiembre, General Penitenciaria) se dice que las prisiones son un mal necesario. 
de resocialización. Por ejemplo, desde el puramente ideológico que destaca, entre otros riesgos, el de su contenido moralizante; el pragmático que afirma la imposibilidad material de hacer efectivo el principio de resocialización.

Por mi parte, sostengo que el ideario de la resocialización ha permitido legitimar muchas instituciones que mitigan la dureza de la privación de libertad y especialmente, la previsión de situaciones de semilibertad que, en último término, redundan en el principio de humanidad de las penas y, también, con independencia de la valoración que merezca como principio, los poderes públicos están obligados a evitar todas las situaciones que perjudican dicho objetivo y/o contrarrestar los efectos desocializadores de la privación de libertad en la línea de las recomendaciones del Consejo de Europa: "El sistema de justicia penal, liberado de procesos socialmente inútiles, cuando no perjudiciales desde el punto de vista de la prevención y la resocialización social, debe evolucionar hacia un sistema social más social que represivo, armonizando la protección de la sociedad para conseguir la reinserción del delincuente. Este sistema de justicia penal parte del principio de que las sanciones penales no privativas de libertad son, desde el punto de vista de la sociedad y del delincuente más ventajosas, y por ello que cuando el interés de la protección de la sociedad no las excluya, son las que deben ser impuestas" ${ }^{\prime 7}$.

\section{Mirada panorámica a las prisiones de mujeres}

Durante años, la mujer ha sido la gran olvidada en el sistema penal y penitenciario, afirmación que encuentra su respaldo en la constatación empírica. Por ejemplo, los estudios criminológicos han ignorado tradicionalmente a la mitad de la población (las mujeres), muchos manuales de criminología de habla hispana siguen sin incluir un apartado dedicado a la mujer, tan solo incorporan algunas secciones sobre violación y prostitución. Igualmente, la mayoría de las teorías de la desviación ignoran a las mujeres casi totalmente ${ }^{8}$ y son muy pocas las investigaciones existentes en este marco.

7. Recomendación (76) del Comité de Ministros del Consejo de Europa.

Una recomendación, que por un lado, pone en tela de juicio los discursos populares que se oponen a las medidas penales que reconocen derechos a los reclusos o mitigan la pena de prisión y, por otro, anima a seguir impulsando una política penal y penitenciaria más humana, potenciando la inversión en servicios y prestaciones penitenciarias y postpenitenciarias y apostando por las alternativas a la cárcel (la viabilidad de las alternativas sigue siendo una incógnita, su puesta en práctica es cara y, además, provoca cambios profundos en las relaciones, no siempre cordiales, entre la justicia y la sociedad). En suma, por una política social enfocada a mejorar la vida de todos los ciudadanos.

8. Un ejemplo de lo que digo es la exposición de R. Merton sobre la estructura social y la anomia. Supone que la "presión para triunfar" alcanza prácticamente a todos en las sociedades modernas. Por tanto, se podría argumentar que las mujeres debían figurar de un modo más prominente que los hombres en las diversas categorías de desviación identificadas por Merton, incluido el delito, dado que existen menos oportunidades para las mujeres de "triunfar" que para los hombres. Pero las cifras de delito, tanto hoy como ayer, nos dicen que las tasas de delincuencia de las mujeres son -o parecen ser- excepcionalmente bajas. 
Pero, ¿qué añade el género en los análisis sobre el sistema penal y penitenciario? Para mí género y sexo no se identifican, no expresan lo mismo. El sexo hace referencia a una realidad biológica inmutable. Mientras que la perspectiva de género es un instrumento de análisis de la realidad que tiende a explicar ciertos fenómenos desde el reconocimiento de que históricamente a la mujer y al hombre se les asignan papeles distintos. Esos papeles no son consustanciales al sexo de cada uno, sino que son culturalmente impuestos; es decir, no son una cuestión biológica, sino de género. Salvo parir y amamantar, los demás roles que se quieren atribuir con exclusividad a la mujer, no son biológicos suyos y, los que tradicionalmente se atribuyen a los hombres, la mujer puede desempeñarlos todos. Es un concepto que se refiere a las diferencias construidas socialmente entre hombres y mujeres, además recoge los procesos que transforman esas diferencias en relaciones de poder y desigualdad. En consecuencia, la perspectiva de género sirve para poner en pie políticas de lo más variado tendentes a modificar la situación de desigualdad impuesta. ${ }^{9}$

Y esto es lo que ha ocurrido en nuestro país con los escasos, pero incisivos estudios, sobre las mujeres presas ${ }^{10}$.

9. Los estudios sobre las mujeres cuentan con un creciente apoyo. Son cada vez más numerosas las recomendaciones y normativas emitidas por organizaciones de carácter nacional e internacional que impulsan los estudios de género. Se pretende legitimar esta área de conocimiento como especialidad de estudio, como categoría de análisis, y como indicador de calidad de cualquier informe, proyecto, diagnóstico, o intervención.

En España, la Constitución española en el artículo 9.2. indica que "Corresponde a los poderes públicos promover las condiciones para que la libertad y la igualdad del individuo y de los grupos en que se integra sean reales y efectivas; remover los obstáculos que impidan o dificulten su plenitud y facilitar la participación de todos los ciudadanos en la vida política, económica, cultural y social". El artículo 14 señala que "Los españoles son iguales ante la Ley, sin que puedan prevalecer discriminación alguna por razón de nacimiento, raza, sexo, religión, opinión o cualquier otra condición o circunstancia personal o social", y en los artículos 15 y 17.1 alude que "todos tienen derecho a la vida y la integridad física y moral, sin que puedan ser sometidos a tortura ni a penas o tratos inhumanos o degradantes" y que "toda persona tiene derecho a la libertad y la seguridad".

Por su parte, la Ley Orgánica para la Igualdad efectiva entre mujeres y hombres, del Ministerio de Trabajo y Asuntos sociales, aprobada el 22 de marzo de 2007 insta a las instituciones a desglosar los datos estadísticos en función de la perspectiva de género. En este sentido, el INE (Instituto Nacional de Estadística) ha creado mecanismos para ofrecer datos e indicadores sobre la situación de los hombres y las mujeres en España desglosados por la variable sexo con objeto de facilitar a los usuarios el acceso a este tipo de información.

10. A lo largo de los más de treinta años de desarrollo de la L.O.G.P. se ha ido compilando un intenso y destacado material descriptivo, crítico, analítico, etc. que ha puesto en tela de juicio la situación de las mujeres en las prisiones españolas así como los logros y fracasos de la intervención socioeducativa desde la perspectiva de género. Como muestra un botón: A. Canteras Murillo (1990), HERRERA, M. (1993), ALMEDA, E. (2002), YAGÜE, C. (2002), MARTíN, M. R. (2005), CASTILLO, J. y RUIZ, M. (2010).

Estos estudios han puesto de manifiesto que las mujeres sufren una doble discriminación, por ser mujer y por ser presa, sin embargo, esta exclusión no comienza en la prisión sino antes debido a que muchas de estas mujeres estaban abocadas a una vida de marginación y delincuencia, a la que vuelven una vez salen de prisión. Una constatación que, desde el principio, cuestiona los principios de rehabilitación y reinserción social que nuestra Carta Magna recoge en su artículo 25.2. 


\subsection{Rasgos sociodemográficos de las mujeres presas}

En los últimos años, el número de presos en España ha experimentado crecimiento espectacular. Este incremento se observa tanto para el caso de los hombres como de las mujeres. Por ejemplo, en 1980 el número de mujeres encarceladas era de 583, en el año 2000 de 3.653 y el día 1 de enero de 2010 la cifra asciende a 6.071 mujeres encarceladas sobre una población total de 75.937 personas, una representatividad paradójica pues sobre las cifras oficiales del censo nacional, la población femenina mantiene una representación de más del 50\% ${ }^{11}$.

Estas cifras indican que el porcentaje de mujeres presas en el Estado español se sitúa alrededor del 8\%, uno de los porcentajes más altos del entorno europeo donde la media no supera el $5 \%{ }^{12}$. Y esto ha sucedido al compás de las sucesivas reformas del Código Penal y en especial el incremento de la penalización de los delitos relativos a la seguridad vial y a la violencia de género.

El motivo más repetido por el que la mujer ingresa en el sistema penitenciario es por el delito contra la salud pública o tráfico de estupefacientes ${ }^{13}$. En cambio, en los hombres es mucho más frecuente que recurran a las actividades contra el patrimonio y el orden socioeconómico, los habituales robos (ver cuadro 1).

En relación a la situación procesal penal, los datos del Ministerio del Interior indican que más del $75 \%$ de las mujeres reclusas se encuentran efectivamente condenadas, la edad media se sitúa en los 35 años, el perfil mayoritario de nuestra población reclusa está representado por personas que han vivido en ambientes desfavorecidos, tienen escasa formación (muchas de ellas son analfabetas) ${ }^{14} y$ no poseen una cualificación profesional clara, existe un porcentaje significativo de reclusas extranjeras que no conocen nuestro idioma y un alto porcentaje de drogodependientes.

11. Según datos oficiales del INE relativo al censo del 1 de enero de 2009, en nuestro país se contemplan 23.628.819 mujeres frente a la población nacional censada cifrada en 46.745.807 personas. www.ine.es .

12. Según datos del Ministerio del Interior, en el año 2010, la tasa de encarcelamiento en España se sitúa en 166 reclusos por 100.000 habitantes, por delante de Gran Bretaña (153), Portugal (104), Francia (96), Italia (92).

13. Desde mi punto de vista, la elección de las mujeres hacia esta actividad criminal -tráfico y venta de estupefacientes- es debido a que es una acción que no conlleva un riesgo evidente para la integridad del autor, además, la implicación de la mujer suele limitarse a engrosar los últimos eslabones de la cadena con la venta a pequeña escala o el transporte entre fronteras. Este hecho supone una de las mayores contradicciones que pueden observarse en nuestro sistema penitenciario debido a la tendencia a endurecer las penas de las políticas penales actuales la cuantía de las condenas que sufren las mujeres frente a los hombres suele ser mayor, a pesar de su menor capacidad criminal, una tendencia que, presumiblemente, cambiará con la reciente modificación del Código penal (el 23 de diciembre de 2010 entró en vigor la reforma del Código Penal operada por Ley Orgánica 5/2010).

14. La mayoría de estas personas son analfabetas funcionales y otro grupo relevante no tiene estudios de educación primaria o no han terminado de completar esta formación. 
Cuadro 1. Tipología delictiva de la población reclusa penada. Ley Orgánica 10/1995, de 23 de noviembre, del Código Penal

\begin{tabular}{|l|r|r|r|}
\hline \multicolumn{1}{|c|}{ Delitos } & \multicolumn{1}{c|}{ Hombres } & \multicolumn{1}{c|}{ Mujeres } & \multicolumn{1}{c|}{ Total } \\
\hline Homicidio y sus formas & 2.942 & 182 & 3.124 \\
\hline Lesiones & 3.118 & 162 & 3.280 \\
\hline Contra la Libertad & 628 & 34 & 662 \\
\hline Contra la Libertad Sexual & 3.632 & 55 & 3.687 \\
\hline Contra el Honor & 22 & 0 & 22 \\
\hline Contra las Relaciones Familiares & 1.588 & 18 & 1.607 \\
\hline Contra el Patrimonio y el orden socioeconómico & 21.606 & 1.412 & 23.018 \\
\hline Contra la Salud Pública & 14.141 & 2.313 & 16.454 \\
\hline Contra la Seguridad del Tráfico & 1.336 & 17 & 1.353 \\
\hline Falsedades & 659 & 78 & 737 \\
\hline Contra la Administración Pública & 69 & 7 & 76 \\
\hline Contra la Administración de Justicia & 1.258 & 66 & 1.324 \\
\hline Contra el Orden Público & 1.612 & 87 & 1.699 \\
\hline Resto de Delitos & 1.505 & 94 & 1.599 \\
\hline Por Faltas & 113 & 12 & 125 \\
\hline No Consta Delito & 387 & 30 & 417 \\
\hline Totales & & 4.568 & 59.184. \\
\hline
\end{tabular}

Fuente: Estadística mensual agosto 2010, total nacional. Dirección General de Instituciones Penitenciarias. Disponible en: http://www.mir.es

Ahondando un poco más en el perfil de la mujer presa, los datos apuntan que la gran mayoría pertenecen a grupos familiares extensos y desestructurados y antecedentes penales y/o toxicológicos, la mayoría no tienen domicilio fijo, más del $70 \%$ son madres y tienen un promedio de tres hijos de los cuales aproximadamente el $70 \%$ son menores de 18 años.

Un porcentaje alto de las mujeres presas son cabeza de familia monoparental, son solteras con hijos o viudas y recae en ellas la responsabilidad de los hijos no emancipados o personas dependientes y el mantenimiento de la unidad familiar.

Las principales ocupaciones antes de ingresar en prisión eran las de vendedoras ambulantes, empleadas de hogar, temporeras, etc..., muchas ha sufrido violencia física o psicológica y, por último, citar que muchas pertenecen a minorías desfavorecidas como es el caso de la etnia gitana. 
Estas mismas fuentes resaltan el fuerte incremento de las mujeres reclusas extranjeras por tráfico de estupefacientes.

3.2. Ejecución penitenciaria desde la perspectiva de género. Ejemplos de intervención socioeducativa

"Si es una mujer la que ha sido penada por la ley, el daño es todavía mayor; porque si al delito del hombre aun sobrevive la familia, es raro que el de la mujer no la disuelva. No podemos detenernos a investigar las causas de esta diferencia: basta consignar que existe. ¿Cómo se rehabilita la mujer delincuente? Su ejemplo es más contagioso, su infamia más indeleble; y si su arrepentimiento sincero es posible y edificante, la sociedad parece mirarle incrédula, ó le considera cuando más como un objeto extraño y aun admirable, pero no tiene aplicación. Los lazos que rompió el delito de la mujer, rotos quedan por lo común para siempre, y la familia pobre que se disuelve puede asegurarse que es familia miserable.

Nótese que el mal de que tratamos tiene mayor gravedad de la que pudiera inferirse considerando los diez y ocho ó veinte mil penados que hay en los presidios, número relativamente corto si se compara al de los que sufren condena en la cárcel, y sobre todo a los que están en ella esperando sentencia definitiva".

Concepción Arenal (1820-1893)

A lo largo de nuestra reciente histórica, la intervención penitenciaria en materia socioeducativa se ha centrado en la población masculina y, en menor medida, en la femenina. No obstante, en los últimos años se están haciendo esfuerzos importantes, apuestas pragmáticas, de intervención específica con mujeres. Como muestra un botón: las unidades de madres y algunas acciones acometidas por Instituciones Penitenciarias en pro de las mujeres presas dentro del plan de igualdad del Estado español.

Las Unidades de Madres están pensadas y diseñadas para que las mujeres con hijos menores de tres años cumplan la pena en un ambiente lo más idóneo posible para el desarrollo del menor.

La legislación española contempla el derecho de las madres reclusas a mantener a sus hijos con ellas hasta que cumplan los tres años. A día de hoy, los datos indican que más de 200 niños viven en los centros penitenciarios junto a sus madres mientras cumplen la condena. Sin embargo, esta comprobado empíricamente que la cárcel no es el lugar más adecuado para que los niños pequeños pasen sus primeros años de vida.

15. Concepción Arenal, Obras completas, tomo decimosexto (El delito y el crimen), Madrid 1897, p. 7 s.

En REDUR se puede consultar mi artículo sobre C. Arenal. Disponible en: http://www.unirioja. es/dptos/dd/redur/numero6/ruidiaz.pdf. 
El pragmatismo penitenciario y la voluntad política firme a conducido a implementar con éxito las Unidades de Madres, espacios ubicados fuera de los recintos carcelarios, diseño y equipamiento están adaptados para cubrir las necesidades de los menores en sus primeros años al tiempo que hacen efectivo el cumplimiento de la pena de las madres.

He de resaltar que esta experiencia es pionera en Europa. Su objetivo se centra en crear un ambiente adecuado para que los niños puedan desarrollarse emocional y educativamente durante el tiempo que tengan que permanecer en el centro, al tiempo que se favorece la reinserción social las madres.

Con la creación de estas nuevas estructuras se pretende segregar definitivamente las Unidades de Madres de los centros penitenciarios, independizarlas de los mismos y dotarlas de completa autonomía penitenciaria para establecer un régimen de convivencia específico.

Se ha diseñado cada elemento estructural, desde su vistoso aspecto exterior a la dotación de espacios educativos, desde la intimidad familiar, que proporcionan unos pequeños apartamentos, a las discretas medidas de seguridad. Todo ello en orden a facilitar un desarrollo armonioso de los menores y una adecuada relación materno filial. ${ }^{16}$

La vida en estos módulos está adaptada a los horarios y necesidades de los niños y transcurre de forma semejante a la de cualquier niño en el medio libre; duermen y desayunan con sus madres, asisten a la escuela infantil, etc.

Las escuelas infantiles disponen de aula de psicomotricidad, aula escolar, comedor y zonas ajardinadas para juegos al aire libre. Están atendidas por personal laboral fijo que programa las clases como en cualquier otro centro infantil.

Otro ejemplo destacado son las Acciones acometidas por Instituciones Penitenciarias en pro de las mujeres presas dentro del plan de igualdad.

Con el mismo pragmatismo y voluntad política del ejemplo anterior, recientemente Instituciones Penitenciarias se comprometió con un programa de acciones de igualdad tendentes a modificar las estructuras organizativas, erradicar los factores de discriminación basados en el género, atención especial a las necesidades de las mujeres presas y, por último, planes para favorecer la erradicación de la violencia de género y paliar sus consecuencias.

El tiempo transcurrido ha sido escaso pero alentador, como muestra un botón: la creación del Observatorio del Programa de Acciones para la Igualdad con más de 25 miembros entre profesionales de Instituciones Penitenciarias y extrapenitenciarios de distintos ámbitos (judicial, académicos, tercer sector,

16. Existe también una Unidad Familiar en el centro penitenciario de Madrid VI para aquellos casos en que ambos miembros de la pareja se encuentren encarcelados. En este centro pueden convivir los padres con sus hijos menores de 3 años, si reúnen un mínimo perfil de seguridad y ofrecen garantía del buen cuidado de los menores. 
etc.) cuya Comisión Técnica se constituyó en junio de 2009. Un impulso en pro de la igualdad muy prometedor.

\section{A modo de conclusión}

Quisiera terminar estas páginas concluyendo que, a mi juicio, la personas (sean mujeres $\mathrm{u}$ hombres) dependen en buena medida de sus condiciones materiales de vida. Por ello, y a pesar de que durante mucho tiempo pensé, basándome en los hechos, de que las cárceles son casi totalmente inútiles a los efectos de disuadir o reinsertar a los reclusos, todos los esfuerzos encaminados a transformar las instituciones penitenciarias son, a todas luces, necesarios y urgentes.

Sostengo que no existe un buen sistema de ejecución penal sin un buen sistema de penas. Cualquier buena intención o propuesta de mejora del entorno penitenciario tiene los días contados si el sistema penal en su conjunto sigue optando por la cárcel como la principal respuesta frente al delito o si se deja dominar por la siempre irracional reivindicación de la retribución y el castigo.

Por otro lado, toda política igualitaria que se quiera aplicar debe estar cimentada en el conocimiento pleno de la realidad. En España, a lo largo de los más de treinta años de desarrollo de la L.O.G.P. se ha ido compilando un intenso y destacado material descriptivo, crítico, analítico, etc. que bajo enfoques teóricos, sociales, psicológicos, pedagógicos y jurídicos variados ha puesto en tela de juicio la situación de las mujeres en las prisiones españolas así como los logros ${ }^{17}$ y fracasos de la intervención socioeducativa desde la perspectiva de género.

El camino recorrido ha sido mucho pero todavía queda un largo camino por recorrer.

\section{Bibliografía}

ALMEDA, E., (2002): Corregir y castigar. El ayer y hoy de las cárceles de mujeres. Barcelona: Ediciones Bellaterra.

BENTHAM, J. (1977): Le Panoptique, precedé de L'oeil du pouvoir, entretien avec M. Foucault. Paris: Belfond.

17. En palabras de la actual Secretaría General de Instituciones Penitenciarias "La Institución Penitenciaria es una pieza ineludible de la política de seguridad de un país y también de la política de intervención social. Estamos convencidos de que solamente construyendo espacios de tratamiento, reeducación y rehabilitación para aquellas personas que un día cometieron un delito podremos dar respuestas eficaces que incrementen nuestra seguridad y nuestra libertad ciudadana" Mercedes Gallizo Llamas, Sistema penitenciario español, Madrid, Servicio de Publicaciones de la Secretaría General de Instituciones Penitenciarias, 2010, consulta virtual gratuita en formato PDF. Disponible en: http://www.mir.es. 
- (1979): El Panóptico. Incluye MIRANDA, M․ J.: Bentham en España. Madrid: La Piqueta.

CANTERAS MURILLO, A. (1990): Delincuencia femenina en España. Un análisis sociológico. Madrid: Centro de Publicaciones del Ministerio de Justicia.

COHEN, S. (1985): Visions of Social Control. Cambridge, Polity Press (trad. castellana de E. LARRAURI, Visiones de control social. Barcelona: P.P.U., 1988).

FOUCAUT, M. (1990): Vigilar y castigar: nacimiento de la prisión, $18^{\mathrm{a}} \mathrm{ed}$. en castellano, $7^{\mathrm{a}}$ ed. en España. Madrid: Siglo XXI de España.

GOFFMAN, E. (1969): Internados. Buenos Aires: Amorrortu.

HERRERA, M. (1993): "Mujeres y prisión". Cuadernos de Política Criminal 49, pp. 330-354.

HULSMAN, L. y BERNAT DE CELIS, J. (1984): Sistema penal y seguridad ciudadana: hacia una alternativa. Barcelona: Ariel.

LARRAURI PIJOAN, E. (1998a): "Criminología crítica: abolicionismo y garantismo". Nueva doctrina Penal, b: 719-753.

- (1998b): "Control del delito y castigo en Estados Unidos", introducción a A. VON HIRSCH, Censurar y Castigar. Madrid: Trotta.

MANJÓN-CABEZA, A. (2009): "La mujer víctima de la violencia de género (Legislación penal y Sentencia del Tribunal Constitucional 59/2008, de 14 de mayo", en Antonio García-Pablos de Molina (Ed.), Víctima, prevención del delito y tratamiento del delincuente. Granada: Comares.

MARTÍN PALOMO, M. T. (2005): Delitos y fronteras. Mujeres extranjeras en prisión. Madrid: Universidad Complutense de Madrid - Instituto de Investigaciones Feministas.

MELOSSI, D. y PAVARINI, M. (1977): Carcere e fabbrica. Alle origini del sistema penitenziario. XVI-XIX. Florencia, II Mulino. Ed. Versión castellana de Xavier Massimi, (1980) Cárcel y fábrica. Los orígenes del sistema penitenciario. (siglos XVI-XIX). México: Siglo XXI.

MIRANDA LÓPEZ, Ma J. (2002): "Cárceles, ¿para qué?", en Política y Sociedad 39 (2), pp. 377-397.

MORRIS, N. (1974): The Future of Imprisonment. Studies in Crime and Justice. Universidad de Chicago Ed. Versión castellana de Nicolás Grab (1978), El futuro de las prisiones. México: Siglo XXI.

NEUMAN, E. y otros (1974): La sociedad carcelaria. Buenos Aires: Depalma.

WAQUANT, L. (2000): Las cárceles de la miseria. Buenos Aires: Manantial.

YAGÜE OLMOS, C. (2002): "Mujer: delito y prisión, un enfoque diferencial sobre la delincuencia femenina", en Revista de Estudios Penitenciarios 249, pp. 135-169. 